\title{
Representações sociais da formação docente em estudantes e professores da Educação Básica
}

\author{
Edna Maria Querido de Oliveira Chamon \\ Universidade de Taubaté - SP
}

\section{Resumo}

Este trabalho analisa as representações sociais sobre a formação docente de um grupo de 513 estudantes de licenciatura em Pedagogia do Estado do Pará, na Região Norte do Brasil, e de um grupo de 369 professores de Educação Básica do Estado de Minas Gerais, na Região Sudeste do Brasil. Procura-se caracterizar a formação em termos da organização de seus elementos constituintes, comparando-se os resultados obtidos para cada grupo a partir das respostas a um questionário. Os questionários foram submetidos a uma análise em componentes principais, com rotação varimax. Nos dois estudos a caracterização da formação docente ocorre em termos do esforço/trabalho individual necessário para ser professor e em termos de competências a serem trabalhadas na formação acadêmica e na prática docente. Uma inversão de prioridades nos dois grupos indica uma evolução das representações sociais de uma visão acadêmica para uma visão de formação enquanto prática social. Palavras-chave: Formação de professores, representação social; professores.

\section{Social Representation of Teacher Education for Undergraduates and Primary Education Teachers}

\begin{abstract}
In this paper we analyze the social representation of teacher training constructed by a group of 513 undergraduates in Education from Pará State, in Brazilian Northern region, and a group of 369 teachers from Minas Gerais State, in Brazilian Southeastern region. Our aim is to characterize the educational process by the organizing its elements, comparing the results obtained for each group based on the responses to a questionnaire. The questionnaires were submitted to a principal component analysis with varimax rotation. In both studies the characterization of teacher education occurs in terms of effort/individual work necessar for a teacher, and in terms of skills to be developed in academic and teaching practice. An inversion of priorities in both groups reveals an evolution of representations from an academic view to an educating view as a social practice.
\end{abstract}

Keywords: Teacher education, social representation, teachers.

\section{Representaciones sociales de la formación docente en estudiantes y profesores de Educación Básica}

\section{Resumen}

Este trabajo analiza representaciones sociales sobre la formación docente de un grupo de 513 estudiantes de licenciatura en Pedagogía del Estado de Pará, Región Norte de Brasil, y de un grupo de 369 profesores de educación básica del Estado de Minas Gerais, Región Sudeste de Brasil. El objetivo es caracterizar la formación en términos de sus elementos constitutivos, comparándose los resultados obtenidos para cada grupo a partir de las respuestas a un cuestionario. Los cuestionarios se sometieron a un análisis de componentes principales, con rotación varimax. En los dos estudios la caracterización de la formación docente ocurre en términos del esfuerzo/trabajo individual necesario para ser profesor y en relación a las habilidades que serán trabajadas en la formación académica y en la práctica docente. Una inversión de prioridades en los dos grupos indica una evolución de las representaciones sociales de una visión académica para una visión de formación como práctica social. Palabras Clave: formación docente; representación social de la formación; profesores. 


\section{1 - Introdução}

Toda sociedade é apoiada na formação dos indivíduos que a compõem, formação que é condição necessária para sua sobrevivência e sua reprodução. Nas sociedades modernas essa formação é fortemente baseada na educação formal, em sua vertente escolarizada. De fato, há mais de dois séculos a educação em seu formato escolar constitui o modo dominante de socialização e formação nessas sociedades. Essa é a maneira privilegiada, entre outras atividades sociais e culturais, de transmitir o conhecimento socialmente acumulado ao longo das gerações.

No Brasil, os professores, atores centrais nesse processo, viram seu número crescer a partir de meados do século passado, quando começou a grande expansão da escolarização básica no país. Esse crescimento vertiginoso em tempo relativamente curto se deu à custa de soluções provisórias (mas que se perpetuam) e adaptações, incluindo "expansão das escolas normais em nível médio, cursos rápidos de suprimento formativo de docentes, complementação de formações de origens diversas, autorizações especiais para exercício do magistério a não licenciados, admissão de professores leigos, etc" (Gatti, \& Barretto, 2009, p. 11).

Se a ampliação da escolarização básica é meritória, mesmo tempo ela coloca desafios significativos para a formação de professores, não apenas em função do grande número de profissionais que deve ser formado, mas também pelas pressões por práticas educativas que apontem para uma sociedade mais justa e democrática e para uma formação cidadã.

Por outro lado, a formação dos professores não é uma via de mão única. Como qualquer processo de formação, constitui-se em uma construção por parte do indivíduo que ao mesmo tempo se modifica nesse processo. Tais processos de construção ocorrem em um dado contexto social e na interação com o outro (individual e coletivo). Esses processos contribuem para a formação identitária do indivíduo e para a construção/atualização de representações sobre a própria formação.

O objetivo deste artigo é estudar a formação enquanto objeto social que é percebido/construído por um grupo e contribui para a construção identitária desse grupo. Propõe-se aqui o estudo das representações sociais da formação por alunos de um curso de licenciatura em Pedagogia, isto é, de professores em formação, e um grupo de professores das séries iniciais da Educação Básica. Mais precisamente, propõe-se o estudo da dinâmica dessa representação social ao longo da formação e da prática docente.

O artigo parte do estudo da tensão entre o conhecimento pedagógico e a ação docente em sala de aula, ou seja, da tensão entre a teoria e a prática docentes. A hipótese básica aqui discutida é a da oposição entre uma lógica de formação e uma lógica das práticas: a primeira pode ser entendida como uma lógica regida por questões de conhecimento, na qual os conceitos compõem um conhecimento discursivo; e a segunda, como uma lógica de atuação em situações complexas de ensino (Franco, 2008).
Essa oposição entre teoria e prática se manifesta em uma evolução das representações sociais dos docentes, desde sua formação inicial até as situações de vivência prática em sala de aula.

Nossa hipótese de base é que inicialmente prepondera uma lógica de formação (teoria), que seria modificada em direção a uma lógica das práticas (prática) à medida que os sujeitos avançam da formação inicial para a atividade profissional docente.

Buscamos inscrever este artigo no debate sobre os contrastes entre a formação docente (especificamente a formação inicial) e a prática em sala de aula, frequentemente descritos na literatura sobre educação (Lima, \& Reali, 2002; Mizukami e cols., 2002; Lopes, 2010); no entanto a contribuição que este trabalho busca para o debate não está na linha das "soluções" para o problema do descolamento entre formação e prática, mas na tentativa de compreender alguns dos fatores que poderiam levar a esse descolamento. Buscamos entender a organização dos conteúdos das representações sociais que os alunos e professores constroem sobre a formação (Chamon, 2011; Gentile, Lima, \& Mazzotti, 2011; Sousa, Villa Bôas, \& Novaes, 2011) e ao mesmo tempo verificar como essa organização evolui ao longo do tempo, à medida que estudantes em formação se tornam docentes praticantes.

\section{2 - Fundamentação teórica}

\section{1- A Formação Docente}

O sentido geral da palavra "formar" é bastante antigo, remontando pelo menos ao século $\mathrm{XI}$, e designa tanto um produto (uma formação geológica) quanto um processo (a formação de um feto ou a formação da língua portuguesa). O sentido pedagógico, por sua vez, é muito mais recente e, aparentemente, foi introduzido numa acepção de formação profissional. Ele torna-se de uso corrente, embora restrito, nos anos 1950, com a introdução dos métodos americanos de training nas empresas. Finalmente, nos anos 1960, a palavra entra para os dicionários com o sentido pedagógico que Ihe é próprio hoje em dia.

Desse ponto de vista, Fabre (1994) percebe três traços fundamentais do formar pedagógico: 1- O percurso, o resultado, a qualificação: "Qual é sua formação? Eu sou formado em Pedagogia"; 2- O sistema. "O plano de formação dos professores"; 3- O processo, "A formação como parte da socialização profissional".

Uma análise lexicográfica simplificada permite, ainda, caracterizar quatro campos semânticos da formação: educação, ensino, instrução e formação propriamente dita (Silva, 2000):

1. A "educação" remete à ideia de nível ou de elevação de nível. Trata-se de uma significação não específica, que designa um desenvolvimento tanto intelectual quanto físico ou moral. 
2. O "ensino" é principalmente ligado ao lado operacional do método e ao aspecto institucional da atividade. O ensino ocorre num quadro institucional, com métodos bem definidos e profissionais qualificados. Ensinar está ligado a aprender, a explicar, a mostrar e demonstrar.

3. A "instrução" se refere aos conteúdos que devem ser transmitidos. Trata-se de transmitir informações a alguém a fim de desenvolver-lhe o espírito e o intelecto. É nesse sentido que falamos de uma pessoa instruída.

4. O "formar" evoca, finalmente, dar ser e forma e, por extensão, organizar e estabelecer. É uma ação global que se direciona a uma transformação profunda da pessoa.

É este último campo semântico que aparece nas discussões mais recentes sobre a formação em geral e a formação docente em especial. A busca de uma formação cidadã e de uma educação emancipatória é atravessada pela noção de transformação integral do indivíduo implicada nessa noção de formar.

Em geral, a literatura educacional identifica pelo menos dois modelos de formação, o modelo linear e o modelo pragmático, que caracterizam as formas como o conhecimento é gerado para a formação docente (Nunes, 2008). O primeiro modelo refere-se à concepção externa - pela comunidade científica - de inovações educacionais. Essas inovações devem ser absorvidas e aplicadas pelos professores de forma passiva, como consumidores de um produto acabado. Já o segundo modelo afirma que o conhecimento gerado na prática é funcional e válido, independentemente de teorias e formalizações científicas. O embate entre esses modelos de formação influencia a forma como as representações sociais são construídas.

\section{1 - A Tensão teoria x prática}

A discussão sobre a primazia da teoria sobre a prática, ou vice-versa, é uma das oposições ou antinomias há muito identificadas que permeiam a organização do pensamento filosófico e do senso comum (Marková, 2006). Talvez a representação alegórica mais conhecida dessa oposição seja o fresco do pintor renascentista italiano Rafael - $A$ Escola de Atenas - que mostra o filósofo Platão apontando para o alto, para as coisas eternas e etéreas (representação alegórica da teoria), e o filósofo Aristóteles que, ao mesmo tempo, aponta para baixo, para o que é concreto (representação alegórica da prática).

A literatura sobre educação discute e critica essa separação, apontando o obstáculo que ela representa para o trabalho docente e propondo formas de superá-lo (ver, por exemplo, Franco, 2008; Nunes, 2008; Alexandre, 2011; Carvalho, 2011; Cruz, 2012).

Sem dúvida, a derivação direta de propostas de uma prática educativa a partir de sistemas teóricos abstratos não se sustenta, como bem demonstrou Carvalho (2011). O que resulta nessas circunstâncias é uma concepção tecnicista da prática, uma concepção não reflexiva, que a vê como um treinamento para realizar tarefas de uma determinada forma (Franco, 2008). A prática docente de caráter formador, em oposição à tecnicista, é aquela que permite a construção de um fazer significativo, uma prática crítica do saber instituído.

Não obstante, a situação oposta, ou seja, a prática como pura empiria, centralizada exclusivamente na experiência imediata do docente, restringe as perspectivas do processo de transformação do ensino e da escola, podendo levar à omissão de variáveis do contexto no qual o próprio docente e os alunos estão inseridos (Cruz, 2008).

Se é fato que o trabalho docente é uma atividade socioprática, aquela que foi praticada muito antes de sobre ela se teorizar e produzir conhecimento (Roldão, 2007), é também certo que a teorização dessa prática, que se seguiu, gerou um grande corpo de conhecimentos sobre essa atividade.Ao interagir com a prática esse corpo de conhecimentos a alimenta e transforma, retomando-se o ciclo. Trata-se, assim, de prática refletida, teorizada, crítica. O oposto disso é o tecnicismo simplista, o "aplicacionismo" de receitas predefinidas.

Essa relação teoria-prática - interativa, de caráter formador, própria de um fazer significativo que reflete sobre si mesmo - é aquela que se encontra consignada na literatura especializada sobre a educação e nas teorias críticas; é aquela que se propõe ser libertadora, ser construtora de sujeitos; é aquela que se almeja para uma real profissionalização docente.

Aqui é de perguntar: seria dessa forma que os docentes, professores formados, ou os estudantes, professores em formação representam essa relação teoria-prática?

No dia a dia da atividade, seja ela docente ou de formação para a docência, nas opiniões, nas crenças, nas comunicações dos sujeitos, como se representa essa relação entre teoria e prática? Como é histórica e social, como evolui essa representação?

\subsection{A perspectiva das representações sociais}

O estudo das representações sociais (RS) permite ver a prática social como caracterizada pela multiplicidade e complexidade de relações por meio das quais se criam e se trocam conhecimentos, tecendo redes que ligam os sujeitos em interação. Nesse sentido, a prática social está ligada a uma rede de relações sociais em que os indivíduos partilham significados, ou seja, está ligada ao fazer, não apenas individual, mas, sobretudo, ao fazer vivenciado em um domínio social. Sob esse aspecto, as representações sociais - que estruturam esse compartilhamento de significados e são estruturadas por ele - estabelecem a relação com as práticas sociais, uma das razões fundamentais para seu estudo.

São as representações sociais o que explica como um grupo se apropria de um objeto social e recria coletivamente seu significado, gerando, a priori, uma orientação para sua prática e, a posteriori, uma justificativa para suas ações. 
Podemos entender uma representação social como uma "forma de conhecimento, socialmente elaborado e partilhado, tendo uma orientação prática e colaborando na construção de uma realidade comum a um conjunto social" (Jodelet, 1989, p. 36).

Assim, a compreensão da maneira como a formação docente é entendida por um grupo - em nosso caso, por grupos diretamente envolvidos com o processo de formação -, passa pela compreensão de como o grupo representa essa formação.

As representações sociais funcionam como um sistema de regulação social que atualiza o sistema cognitivo dentro de um determinado contexto, o que explica tanto as variações interindividuais em um grupo como a orientação geral desse grupo em matéria de comportamento, informação, atitude. A representação social não determina o comportamento, mas delimita o universo de possibilidades (Doise, Clemence, \& Lorenzi-Cioldi, 1992).

\subsection{1- As representações sociais como um campo estruturado}

Jodelet (1989) indica duas grandes orientações no estudo das representações sociais: o campo estruturado e o núcleo estruturante. A primeira linha de análise remete à corrente teórica iniciada por Moscovici (1976) e aos trabaIhos desenvolvidos na Escola de Altos Estudos em Ciências Sociais (EHESS - Ecole de Hautes Etudes en Sciences Sociales), em Paris; a segunda relaciona-se aos trabalhos de Jean-Claude Abric (ver, por exemplo, Abric, 1994a) e do grupo de pesquisadores da Universidade de Provence, em Aix-en-Provence, França.

O presente estudo alinha-se com a primeira corrente, buscando os elementos constituintes da representação (seu conteúdo) e os princípios organizadores que estruturam o campo de representação.

\subsection{2- Gênese e dinâmica das representações sociais}

As representações sociais se apresentam sob dois aspectos: o da imagem (reprodução do real de maneira concreta) e o do conceito (abstração do sentido do real, significação que corresponde à imagem do real). Na formação e na dinâmica das representações sociais dois processos intervêm: a objetivação e a ancoragem. Esses processos "indicam a maneira como o social transforma um conhecimento em representação e como esta representação transforma o social" (Jodelet, 1992, p. 367).

\section{a) O conceito de objetivação}

A objetivação é o processo que torna concreto o que é abstrato. Ela substitui o objeto pela sua imagem, a imagem tornando-se o próprio objeto e não mais sua representação.
A imagem é sempre uma simplificação, necessariamente deformada, do conceito que lhe deu origem.

Uma representação social é vista como forma de verdade, como observa Rouquette (1994, p. 172): "A maior parte do tempo, cada um está convencido de que fala da realidade das coisas, quando apenas exprime sua própria compreensão daquilo que percebe".

Uma das funções da objetivação é facilitar a comunicação dentro de um grupo, embora isso se faça pela dissociação do objeto do quadro científico ou ideológico que lhe dá sentido. O objeto apropriado pelo grupo não se distingue da representação deste objeto. Não existe o sentimento de arbitrário ou relativo com respeito à representação do objeto.

\section{b) O conceito de ancoragem}

A ancoragem diz respeito ao enraizamento social da representação. Sua função é realizar a integração cognitiva do objeto representado em um sistema de pensamento preexistente. Dessa maneira, os novos elementos de conhecimento são colocados numa rede de categorias mais familiares. O sistema de classificação utilizado supõe uma base de representação partilhada coletivamente (Jodelet, 1992), isto é, categorias socialmente estabelecidas. Pode-se dizer que o grupo exprime sua identidade a partir do sentido que ele dá à representação.

Assim, a ancoragem se refere a significações distintas daquelas internas ao conteúdo de uma representação. São as significações que intervêm nas relações simbólicas existentes no grupo social que representa o objeto.

De uma forma resumida, pode-se dizer que a gênese da RS de um objeto por um grupo, na perspectiva do campo estruturado, ocorre por meio de uma simplificação do objeto, guardando-se os aspectos mais salientes para o grupo (objetivação), seguida de uma assimilação desse objeto simplificado a uma rede previamente existente de significados e categorias próprios desse grupo.

A dinâmica ou transformação da RS pode se dar tanto por alteração da objetivação quanto por alteração da ancoragem. No primeiro caso, uma mudança na objetivação pode ocorrer por focalização em novos aspectos do objeto, por exemplo. No segundo caso ocorre o deslocamento social do grupo no espaço da representação, isto é, o grupo se move dentro da rede de significados, gerando outra ancoragem dentro da própria rede já existente (Viaud, 1999).

É essa segunda possibilidade que buscaremos explorar neste artigo, analisando uma possível mudança na ancoragem dos grupos estudados.

\subsection{3- As funções das representações sociais}

Já se mencionou o papel da representação social enquanto sistema de interpretação da realidade e enquanto organizadora de comportamentos e práticas, e agora, são explicitadas as suas funções. De acordo com Abric (1994b), as representações respondem a quatro funções essenciais: 
função do saber, função identitária, função de orientação e função de justificação.

\section{1- Função de saber}

As representações sociais permitem compreender e explicar a realidade, isto é, como os indivíduos adquirem conhecimentos e os integram num quadro assimilável por eles (o senso comum), e tudo isso de modo coerente com seus valores e seu funcionamento cognitivo.

\section{2- Função Identitária}

As representações também têm por função situar os indivíduos e os grupos no campo social. A partir delas, eles são capazes "(...) de elaborar uma identidade social compatível com os sistemas de normas e valores social e historicamente determinados" (Mugny, \& Carugaty, 1985, p. 183, tradução nossa).

\section{3- Função de orientação}

Esta função guia os comportamentos e as práticas por meio de três fatores:

a- A definição da finalidade da situação. determina a priori os tipos de relações pertinentes a um sujeito e, eventualmente, nas situações em que exista uma tarefa a ser cumprida, o tipo de estratégia cognitiva a ser adotado.

b- Um sistema de antecipação e de espera: uma representação não segue o desenrolar de uma interação e não depende dela; ela precede a interação e a orienta.

c- Uma prescrição de comportamento: a representação social reflete a natureza das regras e das ligações sociais e, dessa forma, é prescritiva de comportamentos ou de práticas obrigatórias.

\section{4- Função de justificação}

As representações sociais permitem justificar a posteriori as tomadas de posição e os comportamentos. Elas são um funcionamento que sucede a ação, permitindo aos atores sociais explicar e justificar suas condutas numa situação ou em relação a seus parceiros.

Cumpre notar, particularmente, a relação entre as representações e as práticas sociais. Se as representações têm influência sobre as práticas, estas, em retorno, moldam ou reconstroem as representações. Como veremos na análise dos resultados, a prática social parece operar como motor de uma dinâmica representacional, no sentido de fazer evoluir as representações da formação à medida que se passa da situação de estudante para a de professor.

\section{3 - Método}

\section{1- A análise quantitativa}

O estudo da organização dos conteúdos das representações sociais é feito por meio de métodos e técnicas variadas que são tanto quantitativos quanto qualitativos. A coleta de dados se dá geralmente por meio de "respostas a questionários, associações livres, entrevistas, etc." como indicam Doise e cols. (1992, p.25).

Para estudar a representações sociais e buscar confirmar a hipótese inicial, adotou-se aqui uma abordagem quantitativa baseada em questionário. Essa escolha deve-se em parte aos sujeitos da pesquisa e em parte à natureza da hipótese de pesquisa. De fato, dispondo de uma base de sujeitos bastante ampla, como se verá a seguir, o questionário mostra-se uma forma adequada de coletar informações de todos os sujeitos. Ao mesmo tempo, a organização dos conteúdos da RS pode ser bastante bem analisada por meio de técnicas de análise fatorial, que permitem identificar grandes linhas de força ou grandes eixos organizadores do conteúdo da RS. Uma das primeiras aplicações dessas técnicas em RS foi o trabalho de Elizabeth Lage, em 1978, sobre representações sociais da ciência por estudantes (Lage, 1993).

A partir daí os trabalhos nessa linha se multiplicaram, transformando as diferentes técnicas de análise fatorial em ferramentas de uso comum no estudo das RSs. Um apanhado geral dessas técnicas e de suas aplicações no estudo das RSs pode ser encontrado em Oliveira e Amaral (2007).

\section{2- A Amostra}

A coleta de dados foi realizada a partir de questões fechadas relativas à profissão docente e à atividade do professor. Duas amostras foram consideradas para esta pesquisa: um grupo de estudantes de licenciatura em Pedagogia de uma instituição privada do Estado do Pará, na Região Norte do Brasil, de todos os anos de estudo, no qual foram coletados 513 questionários; e, um grupo de professores da Educação Básica do Estado de Minas Gerais, na Região Sudeste do Brasil, das séries iniciais do Ensino Fundamental, no qual foram coletados 369 questionários. Trata-se, em ambos os casos, de amostras de conveniência.

A escolha de duas amostras distintas foi feita para permitir avaliar as diferenças entre as RSs de estudantes e as de professores. Essa forma de estudo transversal, apesar de suas limitações, permite analisar a hipótese de evolução das RSs estabelecida no início deste artigo. Embora os grupos sejam distintos, um mesmo estudo realizado com os dois grupos fornece pistas de como evoluem as RSs à 
medida que se passa da condição de estudante para a de professor.

\section{3 - 0 questionário}

Para ambos os grupos foi apresentado um conjunto de questões fechadas, contendo afirmações sobre a formação docente. O respondente deveria indicar sua concordância ou não para cada afirmação por meio de uma escala do tipo Likert de cinco níveis que variavam de (1) Discordo totalmente até (5) Concordo totalmente.

A confiabilidade do questionário foi avaliada por meio do coeficiente Alfa de Cronbach, tendo-se obtido um valor de 0,7 , o que é satisfatório para a coerência interna do instrumento.

O conjunto de variáveis utilizadas para a análise está indicado no Quadro 1. Cada variável corresponde a uma das afirmações do questionário sobre a qual o sujeito se manifestou na escala de Likert. Essas afirmações diziam

\begin{tabular}{|l|l|}
\hline Afirmação & Variável \\
\hline Habilidades adquiridas na prática docente & HAB \\
\hline Curso de qualidade (conteúdo) & CURSO \\
\hline Aperfeiçoamento contínuo & APERF \\
\hline Trabalho individual & TRAB_IND \\
\hline Trabalho em equipe & TRAB_EQP \\
\hline Traços pessoais & TRACOS \\
\hline Motivação para a profissão & MOTIVA \\
\hline
\end{tabular}

Quadro 1- Afirmações/Variáveis utilizadas na análise da formação docente

respeito à questão geral: "No que consiste a formação de um professor?"

\section{4 - A técnica de análise}

A análise dos dados foi feita separadamente para cada amostra, por meio de uma análise em componentes principais seguida de uma rotação varimax. Utilizou-se, para essas análises, o software Statistica ${ }^{\odot}$.

Basicamente, os dados foram codificados em uma matriz na qual as linhas correspondem aos sujeitos respondentes, e as colunas, às variáveis do questionário. A Análise em Componentes Principais (ACP) foi, então, aplicada a essa matriz.

AACP alinha-se entre as chamadas técnicas fatoriais de análise, as quais permitem identificar as "linhas de força" que organizam um conjunto de variáveis. A ACP é um método essencialmente descritivo que tem por objetivo apresentar, de forma econômica, a informação contida numa tabela de dados. No caso do presente estudo, como indicado a seguir, a ACP vai permitir agrupar as variáveis em eixos que caracterizam os grandes princípios organizadores das RSs.

Assim, nas aplicações para os estudos em RS, a ACP permite uma análise dos principais fatores que organizam o fenômeno que se está analisando. Detalhes da aplicação dessa técnica aos estudos em RS podem ser vistos nos textos de Doise e cols. (1992) e de Oliveira e Amaral (2007).

\section{4- Resultados obtidos}

\section{1- Estudantes de Pedagogia}

Essa amostra era composta de 513 respondentes. A análise em componentes principais (principal components) está indicada na tabela 1. A partir desses resultados podemos perceber que os três primeiros eixos extraídos explicam $63 \%$ da variância das respostas.

Tabela 1. Análise em componentes principais - estudantes de Pedagogia.

\begin{tabular}{ccccc}
\hline & Eigenval & \%Total Variance & Cumul. Eigenval & Cumul \% \\
\hline 1 & 2,19 & 31,28 & 2,19 & 31,28 \\
2 & 1,25 & 17,8 & 3,43 & 49,06 \\
3 & 1,01 & 14,47 & 4,45 & 63,53 \\
4 & 0,80 & 11,43 & 5,25 & 74,96 \\
5 & 0,67 & 9,59 & 5,92 & 84,54 \\
6 & 0,62 & 8,87 & 6,54 & 93,41 \\
\hline
\end{tabular}

Tabela 2. Carga dos fatores - estudantes de Pedagogia.

\begin{tabular}{lccc}
\hline & Fator 1 & Fator 2 & Fator 3 \\
\hline HAB & $\mathbf{0 , 7 6}$ & 0,10 & 0,11 \\
CURSO & $\mathbf{0 , 8 4}$ & $-0,032$ & 0,10 \\
APERF & $\mathbf{0 , 7 5}$ & 0,012 & 0,10 \\
TRAB_IND & $-0,050$ & $\mathbf{0 , 7 5}$ & $-0,27$ \\
TRAB_EQP & 0,080 & $-0,24$ & $\mathbf{0 , 8 0}$ \\
TRACOS & 0,20 & 0,31 & $\mathbf{0 , 6 9}$ \\
MOTIVA & 0,10 & $\mathbf{0 , 7 1}$ & 0,25 \\
\hline
\end{tabular}

A tabela 2 indica os resultados para a carga dos fatores, isto é, a contribuição de cada variável para os três primeiros fatores selecionados. Uma rotação varimax foi realizada nos eixos. A tabela 2 indica, para cada fator, as variáveis que mais significativamente contribuem para a definição desse fator (variáveis em destaque). 


\section{2 - Professores da Educação Básica}

Essa amostra era composta de 369 respondentes. A análise em componentes principais (principal components) está indicada na tabela 3 . A partir desses resultados podemos perceber que, da mesma forma que para a análise anterior, os três primeiros eixos extraídos explicam $63 \%$ da variância das respostas.

Tabela 3. Análise em componentes principais - professores da Educação Básica.

\begin{tabular}{ccccc}
\hline & Eigenval & \% total Variance & Cumul. Eigenval & Cumul \% \\
\hline 1 & 2,48 & 35,50 & 2,48 & 35,50 \\
2 & 1,16 & 16,52 & 3,64 & 52,02 \\
3 & 0,80 & 11,44 & 4,44 & 63,47 \\
4 & 0,79 & 11,35 & 5,24 & 74,81 \\
5 & 0,73 & 10,40 & 5,97 & 85,22 \\
6 & 0,59 & 8,46 & 6,56 & 93,67 \\
\hline
\end{tabular}

De maneira análoga à análise precedente, a tabela 4 indica os resultados para a carga dos fatores, isto é, a contribuição de cada variável para os três primeiros fatores selecionados. Uma rotação varimax foi também realizada nos eixos. A tabela 4 indica, para cada fator, as variáveis que mais significativamente contribuem para a definição desse fator (variáveis em destaque).

Tabela 4. Carga dos fatores - professores da Educação Básica.

\begin{tabular}{lccc}
\hline & Fator 1 & Fator 2 & Fator 3 \\
\hline HAB & 0,52 & 0,29 & 0,23 \\
CURSO & 0,41 & 0,047 & $\mathbf{0 , 7 1}$ \\
APERF & 0,28 & 0,027 & $\mathbf{0 , 7 5}$ \\
TRAB_IND & $-0,31$ & $\mathbf{0 , 6 9}$ & 0,44 \\
TRAB_EQP & $\mathbf{0 , 6 7}$ & $-0,044$ & 0,28 \\
TRACOS & $\mathbf{0 , 7 8}$ & 0,044 & 0,19 \\
MOTIVA & 0,31 & $\mathbf{0 , 8 2}$ & $-0,15$ \\
\hline
\end{tabular}

\section{5 - Análise dos resultados}

\section{1 - Identificação dos fatores}

Em ambos os grupos analisados foi obtido o mesmo conjunto de fatores representativo das respostas ao questionário. Esses fatores são definidos, nos dois casos, essencialmente pelo mesmo conjunto de questões, a saber: conteúdo da formação, atributos internos e aspectos sociais.
FATOR - Conteúdo da formação

A formação do professor consiste em cursos de qualidade - variável CURSO;

A formação do professor consiste em aperfeiçoamento continuo - variável APERF.

Esse fator corresponde às variáveis relacionadas com o conteúdo da formação, com sua dimensão epistêmica. Dessa forma, denominamos esse fator "conteúdo da formação".

Notemos que, no grupo dos estudantes de Pedagogia, esse fator também é composto pela variável $H A B$, que corresponde à questão "A formação do professor consiste em habilidades adquiridas em sala de aula". Essa variável também aparece para o grupo de professores da Educação Básica, mas com importância (carga do fator) muito menor.

FATOR - Atributos internos

A formação do professor consiste no trabalho individual variável TRAB_IND;

A formação do professor consiste no interesse de cada um - variável MOTIVA.

Esse fator corresponde às variáveis relacionadas com a subjetividade, com características intrínsecas ao sujeito, com sua dimensão psicológica. Dessa forma, denominamos esse fator de "atributos internos".

FATOR - Aspectos psicossociais

A formação do professor consiste no trabalho em equipe - variável TRAB_EQP;

A formação do professor consiste em traços pessoais variável TRACOS.

Esse é um fator mais transversal, entre as dimensões social e psicológica, que correspondem a variáveis relacionadas tanto com a subjetividade quanto com as características sociais do sujeito. Dessa forma, denominamos esse fator de "aspectos psicossociais".

\section{2- Comparação entre os grupos}

Notemos inicialmente que essa composição de fatores parece abarcar as dimensões epistêmicas, psicológicas e sociais da formação. Nesse sentido, ainda que a correspondência não seja perfeita, seria possível aproximar esses fatores das três lógicas da formação propostas por Fabre (1994): lógica epistêmica, a lógica psicológica e a lógica socioprofissional. As duas primeiras correspondem às dimensões de conteúdo e psicológica de nosso estudo; já a lógica socioprofissional, na descrição de Fabre, é aquela da adap- 
tação aos contextos culturais ou profissionais, a qual não corresponde completamente à dimensão social encontrada em nossa análise, mas está a ela associada. Uma aplicação desse modelo ao processo de educação continuada pode ser encontrada em Chamon (2006).

Observemos em seguida - e esta é a questão central associada aos resultados obtidos - que, muito embora os mesmos fatores estejam presentes nos dois grupos, sua organização difere entre eles.

O grupo de estudantes de Pedagogia apresenta a seguinte distribuição de fatores em suas respostas às questões:

Fator 1 - Conteúdo da formação: $31 \%$ da variância total explicada;

Fator 2 - Atributos internos: $18 \%$ da variância total explicada;

Fator 3 -Aspectos psicossociais: 14\% da variância total explicada.

Já o grupo de professores da Educação Básica apresenta a seguinte distribuição de fatores em suas respostas:

Fator 1 - Aspectos psicossociais: $35 \%$ da variância total explicada;

Fator 2 - Atributos internos: $17 \%$ da variância total explicada;

Fator 3 - Conteúdo da formação: $11 \%$ da variância total explicada.

É bastante clara a inversão entre os fatores 1 e 3 nos dois grupos. Aparentemente, a questão do conteúdo da formação, que é o mais importante fator explicativo da dispersão das respostas entre os alunos, perde esse poder explicativo no grupo de professores, sendo substituída por aspectos subjetivos e sociais.

Dito de outra forma, as respostas dos professores são mais homogêneas nas questões sobre conteúdo da formação relativamente aos alunos; por outro lado, as respostas dos alunos são mais homogêneas nas questões sobre aspectos subjetivos e sociais da formação relativamente aos professores.

Aparentemente, as certezas e as incertezas sobre a formação são mutáveis e evoluem com a prática social. Enquanto licenciandos, os indivíduos estão relativamente mais de acordo quanto às questões psicológicas e psicossociais do que quanto às questões de conteúdo. O inverso ocorre com os professores.

\section{3 - Dinâmica das representações}

Os resultados obtidos apontam na direção da hipótese apresentada: há uma evolução das representações sociais dos sujeitos entre a formação e a atividade prática da docência. Além disso, os resultados sugerem que essa evolução se dá como deslocamento dentro do espaço de representação, e não como construção de outra e completamente nova representação do objeto.
De fato, o conjunto de fatores extraídos pela análise fatorial é essencialmente o mesmo nos dois grupos, o que indica que a organização dos conteúdos da representação obedece a um mesmo conjunto de princípios organizadores; no entanto, esse conjunto de princípios se organiza diferentemente em cada grupo, como é mostrado pela inversão entre os fatores já comentada. Assim, a evolução da RS parece se dar por modificações no processo de ancoragem, com saliência em aspectos distintos conforme o grupo (estudantes ou professores) que se considera.

\section{6 - Considerações finais}

As análises apresentadas apontam duas considerações importantes sobre o processo de formação docente. A primeira, de caráter mais teórico, mostra a potencialidade do modelo de análise da formação apresentado por Fabre (1994). Embora com limitações (particularmente notável é a ausência de uma dimensão associada aos aspectos políticos e sociais), o modelo representa uma grade de leitura efetiva para analisar processos de formação, em especial, neste caso, a formação docente.

A segunda consideração diz respeito à organização das respostas obtidas e, em particular, à inversão entre fatores que foi observada. Embora os dois grupos tenham sido analisados separadamente e não seja possível, sem estudos suplementares, assegurar que as variações nas respostas entre os dois grupos sejam homogêneas, pode-se inferir uma diferença de ênfase nas respostas desses dois grupos. Enquanto o grupo de licenciandos se posiciona fortemente em termos de conteúdo da formação (fator predominante da análise para esse grupo), o grupo de professores é marcado pelos aspectos subjetivos e sociais. O que é divisor de águas para um grupo parece consensual para o outro, e vice-versa.

Como indicado, esse posicionamento distinto entre os estudantes e professores na rede de significados na qual se ancora a representação, aponta para uma mudança ou evolução na RS da formação entre os dois grupos. Como os princípios organizadores (os fatores que organizam a RS) são equivalentes nos dois grupos, pode-se concluir que a evolução se dá por mudanças no processo de ancoragem, e que essas mudanças ocorrem na passagem da formação docente para a prática docente.

Como já foi comentado anteriormente, o alcance dessas conclusões é limitado e outros estudos seriam necessários para corroborar esses resultados. Particularmente, um estudo longitudinal, que acompanhasse um mesmo grupo desde o início da formação até a entrada na docência e ao longo de sua prática, seria fundamental para mostrar as mudanças nas RSs. Uma vez que tais estudos são de difícil execução, a replicação de estudos transversais, com outros grupos de estudantes e professores, reforçaria as conclusões sobre a dinâmica das RSs.

Provisoriamente, então, pode-se afirmar que os resultados aqui obtidos mostram uma evolução na representação dos professores à medida que terminam sua formação 
e entram na vida profissional. O que é central na formação parece se deslocar de seu conteúdo para aspectos psicossociais que se consolidam ao longo do fazer docente.

\section{Referências}

Abric, J.-C. (1994a). L'organisation interne des représentations sociales : système central et système périphérique. Em C. Guimelli (ed.) Structures et transformations des représentations sociales (pp. 73-84). Neuchâtel: Delachaux \& Niestlé.

Abric, J.-C. (1994b). Pratiques sociales et représentations. Paris: Presses Universitaires de France.

Alexandre, A.F. (2011). Pesquisa acadêmica e prática educativa como um problema sociológico. Cadernos de Pesquisa, São Paulo, 41 (143), 502-515.

Carvalho, J.S.F. (2011). A teoria na prática é outra? Considerações sobre as relações entre teoria e prática em discursos educacionais. Revista Brasileira de Educação, 16 (47), 307-322.

Chamon, E.M.Q.O. (2006). Um modelo de formação e sua aplicação em educação continuada. Educação em Revista (UFMG), 44, 89109.

Chamon, E.M.Q.O. (2011). A representação da formação para professores em um processo de formação continuada. Em Anais da VII Jornada Internacional e V Conferência Brasileira sobre Representações Sociais, (CD ROM). Vitória, ES.

Cruz, G.B. (2012). Teoria e prática no discurso de pedagogia. Educação e Pesquisa, São Paulo, 38 (1), 149-164.

Doise, W., Clemence, A., \& Lorenzi-Cioldi, F. (1992). Représentations sociales et analyse de données. Grenoble: Presses Universitaires de Grenoble.

Fabre, M. (1994). Penser la formation. Paris: Presses Universitaires de France.

Franco, M.A.S. (2008). Entre a lógica da formação e a lógica das práticas: a mediação dos saberes pedagógicos. Educação e Pesquisa, São Paulo, 34 (1), 109-126.

Gatti, B.A., \& Barreto, E.S.S. (2009). Professores do Brasil: impasses e desafios. Brasília: UNESCO.

Gentile, M., Lima, R.C.P., \& Mazzotti, T.B. (2011). Saberes da prática na formação: representações sociais de alunas de pedagogia. Revista Diálogo Educacional, 11, 331-351.

Jodelet, D. (1989). Représentations sociales: un domaine en expansion. Em Jodelet, D. (ed.). Les représentations sociales (pp. 31-61). Paris: Presses Universitaires de France.
Jodelet, D. (1992). Représentation sociale: phénomènes, concept et théorie. Em S. Moscovici (ed.) La psychologie sociale (pp. 357389). Paris: Presses Universitaires de France.

Lage, E. (1993). Lycéens et pratiques scientifiques. Comment les sciences deviennent une passion. Paris: L. Harmattan.

Lima, S. \& Reali, A.M.M.R. (2002). O papel da formação básica na aprendizagem profissional da docência (aprende-se a ensinar nos cursos de formação básica?). Em Mizukami, M.G.N. \& Reali, A.M.M.R. (Orgs.) Formação de professores, práticas pedagógicas e escola (pp. 217-235). São Carlos: EDUFSCar.

Lopes, R.P. (2010). Da licenciatura à sala de aula: o processo de aprender a ensinar em tempos e espaços variados. Educar em Revista, Curitiba, 36, 163-179.

Marková, I. (2006). Dialogicidade e representações sociais. As dinâmicas da mente. Petrópolis, RJ: Vozes.

Mizukami, M.G.N. e cols. (2002). Escola e aprendizagem da docência: processos de investigação e formação. São Carlos: EDUFSCar.

Moscovici, S. (1976). La psychanalyse, son image et son public. Paris: Presses Universitaires de France, 2. ed.

Mugny, G. \& Carugaty, F. (1985). L'intelligence au pluriel. Cousset: DelVal.

Nunes, D.R.P. (2008). Teoria, pesquisa e prática em Educação: a formação do professor-pesquisador. Educação e Pesquisa, São Paulo, 34 (1), 97-107.

Oliveira, A. \&Amaral, V. (2007). A análise factorial de correspondências na investigação em psicologia: Uma aplicação ao estudo das representações sociais do suicídio adolescente. Análise Psicológica, 2 (25), 271-293.

Roldão, M.C. (2007). Função docente: natureza e construção do conhecimento profissional. Revista Brasileira de Educação, 12 (34), 94-181.

Rouquette, M-L. (1994). Sur la connaissance des masses. Grenoble: Presses Universitaires de Grenoble.

Silva, A.M.C. (2000). A formação contínua de professores: Uma reflexão sobre as práticas e as práticas de reflexão em formação. Educação e Sociedade, Campinas, 21 (72), 89-109.

Sousa, C.P., Villas Bôas, L.P.S. \& Novaes, A.O. (2011). Contribuições dos estudos de representações sociais para a compreensão do trabalho docente. Em A.M.O. Almeida, M.F.S. Santos \& Z.A. Trindade (Orgs.) Teoria das Representações Sociais - 50 anos (pp. 625-652). Brasília: Technopolitik. 
Viaud, J. (1999). Principes organisateurs et représentations sociales de l'économie: genèse et dynamique. Revue Internationale de Psychologie Sociale, 12 (2), 79-105.

Recebido em : 13/02/2013

Reformulado em : 10/12/2013

Aprovado em : 29/01/2014

\section{Sobre autora}

Edna Maria Querido de Oliveira Chamon (edna.chamon@gmail.com)

Doutora em Psicologia do Desenvolvimento Humano / Pós-doutora em Educação na Universidade de Taubaté

Este trabalho contou com o apoio financeiro do CNPq, na forma de bolsa de pesquisa e apoio ao projeto. 